\title{
Hijos de la peste. Una historia de las epidemias en el Perú de Marcel Velázquez Castro
}

\section{Abraham Vargas Bautista ${ }^{1}$}

Universidad Autónoma de Madrid. Madrid, España

Universidad Tecnológica del Perú. Lima, Perú

C19143@utp.edu.pe

ORCID: https://orcid.org/0000-0002-7341-9297

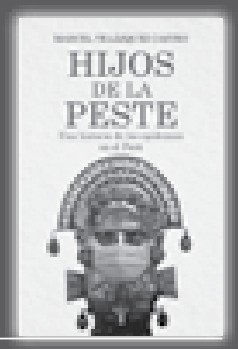

Citar como: Vargas, A. (2021). Hijos de la peste. Una historia de las epidemias en el Perú de Marcel Velázquez Castro. Desde el Sur, 13(2), e0025.

Marcel Velázquez Castro, profesor de Literatura en la Facultad de Letras y Ciencias Humanas de la Universidad Nacional Mayor de San Marcos, nos presenta Hijos de la peste. Una historia de las epidemias en el Perú (2020), un texto escrito en pandemia y desde el aislamiento social. Este libro se propone realizar una crítica a nuestra sociedad en tiempos de la covid-19, pero desde la cultura. El estudio de Velázquez Castro no es un discurso aislado, sino que forma parte de una tradición que se ha formado relativamente en poco tiempo, y de la cual nuestro país no se ha mantenido al margen; es más, nuestros investigadores han contribuido al fortalecimiento del debate desde las humanidades y ciencias sociales.

Tras la llegada de la pandemia a nuestro país se publicó Crónica del gran encierro. Pensando el Perú en tiempos de pandemia (2020), conjunto de artículos de distintos autores que indagan sobre el origen de los problemas estructurales del Perú que generaron una respuesta poco eficiente ante la crisis sanitaria. El coronavirus y los retos para el trabajo de las mujeres en América Latina (2020) es otro estudio que también fue presentado el primer año de pandemia en nuestro país. Este trabajo fue elaborado por el Grupo de Análisis para el Desarrollo (GRADE) y se ocupa de estudiar los estragos de la pandemia en el ámbito laboral. Asimismo, advierte que durante el aislamiento social la brecha de género ha aumentado debido al incremento del trabajo doméstico, que, por lo general y en mayor medida, recae sobre las mujeres. El crecimiento del trabajo no remunerado en el hogar ha impedido que las mujeres accedan a actividades asalariadas.

1 Graduado en Literatura por la Universidad Nacional Mayor de San Marcos. Magíster en Estudios Latinoamericanos por la Universidad Federal de Integración Latinoamericana (Brasil). Es doctorando del programa de Estudios Hispánicos de la Universidad Autónoma de Madrid y docente del Departamento de Humanidades de la Universidad Tecnológica del Perú. 
También destaca el libro de Edilberto Jiménez, Nuevo coronavirus y buen gobierno (2021), donde el retablista y antropólogo expone, desde el dibujo, las desigualdades sociales que ha agudizado la pandemia.

Lamentablemente, el análisis de la pandemia desde las ciencias sociales no ha tenido cabida en los medios de comunicación locales. Pese a ello, el propio Velázquez Castro reconoce que los medios, esta vez, han hecho bien en darle más espacio a la ciencia para informar sobre esta enfermedad que azota el mundo; sin embargo, es importante notar que el trabajo de los medios de comunicación no ha sido riguroso, a tal punto que han permitido darle espacio a declaraciones de videntes o pseudocientíficos ${ }^{2}$. De haber dado espacios a reflexiones académicas respaldadas por evidencia científica, sabríamos que los errores que hoy estamos cometiendo ya los habíamos cometido décadas atrás.

Hijos de la peste es un ensayo que expone que nuestra experiencia contemporánea atípica tiene, más bien, todo de típica. Según avanzamos en la lectura, va perdiendo sentido una de las frases más repetidas desde el inicio de la pandemia: «La vida luego del coronavirus ya no será la misma». Pero el problema es justamente ese, que la vida tras un episodio de crisis sanitaria vuelve a ser la misma: nuestro Estado seguirá siendo ineficiente, nuestras ciudades no serán más limpias, volveremos a echarle la culpa a los «otros» de nuestros males. Y para un próximo episodio similar volveremos a decir que la epidemia ha evidenciado que el capitalismo peruano ha fracasado: gran verdad que se descubre con frecuencia y sin pandemia de por medio.

El libro de Marcel Velázquez está organizado en cuatro ensayos que analizan las epidemias en el Perú, desde la historia, la violencia, el miedo y el humor. En estos textos que conforman el libro, analiza diversas epidemias en nuestro país, como la fiebre amarilla (1868-1869), la peste bubónica (1903), la llamada «gripe española» (1918-1920) y el cólera (1991).

Al andar por las páginas de estos ensayos, no podemos menos que reírnos e indignarnos de nosotros mismos. Marcel Velázquez advierte que la sociedad peruana no ha cambiado mucho su forma de pensar desde el siglo XIX o inicios del XX. Pese a los avances en ciencias médicas y en biología, seguimos prefiriendo los rezos a los medicamentos, continuamos confiando más en las recomendaciones de periodistas desinformados que en las evidencias científicas difundidas por instituciones de salud. $Y$, por si fuera poco, nos (re)enteramos de que las taras del racismo y la

2 Puede revisarse el caso del falso científico Jorge Cuyubamba en Llanos (2020). 
xenofobia asociadas al origen de las enfermedades no son situaciones nuevas, sino muy comunes. Lo que sí ha cambiado es que ahora mucha más gente puede mantenerse informada de las medidas a tomar para evitar el contagio, de cómo van las estadísticas de infectados y fallecidos, pero también puede desinformarse y entrar en pánico por las fake news ${ }^{3}$ que se crean tan fácilmente por las redes sociales.

En el primer ensayo se realiza un análisis histórico de las epidemias. Se nos recuerda cómo distintas pestes contribuyeron a la victoria de los conquistadores sobre los pueblos mayas e incas. Obviamente estas epidemias estaban revestidas de un carácter mágico-religioso, que entendía a las enfermedades como castigos divinos (idea que aún sigue vigente), tanto por las religiones nativas como por el catolicismo. Pero las enfermedades no solo fueron un castigo que alguna deidad imponía a los humanos, sino también un pretexto para ejercer violencia contra un «otro» que trajo la bacteria o el virus. El rechazo absoluto a los que caían enfermos, así como la incineración de sus casas y pertenencias, eran acciones cotidianas hacia los primeros años del siglo XX, cuando imperaba la peste bubónica. La prensa gráfica nacía por aquella época y las imágenes de recintos quemándose como medida sanitaria, la clausura de quintas y los carruajes recogiendo infectados eran noticias habituales. La predilección de la prensa por buscar a los protagonistas de sus historias entre los migrantes nacionales y extranjeros que vivían hacinados en los barrios pobres de Lima contribuyó a estigmatizar a los sectores populares.

Esta acción de la prensa desencadenó el miedo en nuestra sociedad, que es justamente el tema que se aborda en el segundo ensayo. Los carruajes que transportaban enfermos se volvieron habituales en Lima, al igual que el temor a los pacientes y al conductor, que la chismosa población limeña veía como un agente transmisor de virus o bacterias y de malas noticias. La prensa resaltaba los rasgos indígenas de quien se dedicaba a esta labor, y los limeños culpaban a los encargados del traslado de enfermos de esparcir la enfermedad. El temor y rechazo hacia estos personajes racializados pronto se convirtieron en violencia física. El chofer del carruaje no solo debía preocuparse de no contagiarse del enfermo, sino también de salir ileso de la turba que lo quería linchar como una forma de protegerse y alejarlo del vecindario.

3 Sobre los efectos de la desinformación o noticias falsas pueden consultarse los estudios de Nieves-Cuervo, Manrique-Hernández, Robledo-Colonia y Grillo Ardila: (https://iris. paho.org/bitstream/handle/10665.2/53901/v45e442021.pdf?locale-attribute=pt), y de Espinoza-Portilla y Mazuelos-Cardoza (http://scielo.sld.cu/scielo.php?script=sci_arttext\&pid $=$ S2307-21132020000200002). 
Estos episodios de inicios del siglo pasado se actualizaron en esta pandemia. Los primeros meses de cuarentena, todos los días a las ocho de la noche, sin excepción, aplaudíamos como agradecimiento al personal de salud, policial y militar, por estar en «la primera línea de batalla contra el virus». Curiosamente, el personal de salud inquietaba la tranquilidad del vecindario, y con gritos e insultos se exigía que la persona por la que habían aplaudido la noche anterior, en reconocimiento a su labor y valentía, pasara su cuarentena en otro lugar para salvaguardar la salud del barrio. Asimismo, el personal de salud fue recriminado por los familiares de los fallecidos, quienes no comprendían que el virus, la mala gestión del Estado y la imprudencia social podían más que los conocimientos médicos ${ }^{4}$.

En el siguiente capítulo se reflexiona desde la violencia. Se nos hace retroceder hasta los años 90, cuando la violencia terrorista ejercida por Sendero Luminoso asolaba con fuerza a nuestro país. No solo los coches bomba y los «ajusticiamientos populares» exterminaron a miles de nuestros compatriotas, sino también la bacteria Vibrio cholerae. Según se indica en el primer ensayo de este apartado:

La epidemia del cólera en 1991 fue parte de una tormenta perfecta, porque ocurrió con una feroz crisis económica, una acelerada descomposición social y un conflicto armado interno en su fase más violenta. Los tres últimos años del gobierno de Alan García fueron catastróficos: hiperinflación, pobreza, detenidos-desaparecidos en la ciudad, genocidios en la sierra, desplazados internos, migración masiva al exterior. En sus inicios, el fujimorismo prosiguió por este camino estrellado de pobreza y sangre (p. 117).

Este resumen claro y objetivo de nuestra realidad nacional en tiempos del cólera nos pretende mostrar que los problemas sanitarios nunca llegan solos. Por ello, uno de los primeros ministros de Salud en asumir el cargo en plena crisis sanitaria, Víctor Zamora, propició la creación de un grupo interdisciplinar en ciencias sociales con miras a pensar soluciones pospandemia. Retornar a la normalidad, al trabajo en oficina y a los estudios presenciales supondría todo un reto social, ya que más de la mitad de la población a nivel mundial debió entrar en cuarentena de forma

$4 \mathrm{Al}$ respecto, pueden consultarse las siguientes noticias sobre agresiones al personal de salud:

https://larepublica.pe/sociedad/2021/05/15/medicos-son-agredidos-por-familiares-depacientes-en-arequipa-Irsd/

https://peru21.pe/vida/salud/exigen-penalizacion-agresiones-medicos-476045-noticia/

https://elcomercio.pe/peru/medicos-agredidos-la-otra-lucha-a-la-que-se-enfrentan-loshombres-y-mujeres-de-bata-blanca-durante-la-pandemia-coronavirus-peru-covid-19noticia/?ref=ecr 
abrupta; asimismo, el cierre de fronteras y la adaptación a la virtualidad generaron una serie de cambios en las formas de relacionarnos y de redefinirnos como sociedades. Infelizmente el equipo de trabajo referido no tuvo mayor impacto en la manera de organizarnos frente al virus, y ello se refleja en el número contagios y fallecidos que llevamos contando.

Las crisis políticas y económicas siempre agravan las emergencias sanitarias, tal como hoy ocurre con la pandemia de la covid-19. En año y medio de estado de emergencia por coronavirus hemos tenido tres presidentes, y a un mes de la segunda vuelta electoral, y a dos meses del cambio de gobierno, podríamos tener otro más, si el Congreso cumple sus amenazas 5 . Quizá ya no podamos hablar de crisis económica como en la epidemia del cólera (aunque esto es muy discutible), pero definitivamente estamos en medio de una crisis de nuestras instituciones políticas, y es difícil determinar cuál de las crisis (sanitaria o política) es la que nos ha causado más daño. Es importante entender que la corrupción y la casi inexistencia de partidos políticos sólidos y representativos nos han llevado al límite. Asimismo, la ausencia de líderes ha hecho que los peruanos no sepamos en quién confiar o en quién depositar nuestra esperanza. Aquellos en quienes reconocíamos algún liderazgo nos han decepcionado, tanto individuos como instituciones; basta solo pensar en el caso más palpable, en aquel candidato que encabezó la emblemática Marcha de los Cuatro Suyos, que hizo caer un gobierno dictatorial y corrupto. Ese mismo político, bajo el lema de «sano y sagrado», hoy es investigado por corrupción.

Otro problema que ha flagelado nuestra sociedad es el racismo, que, si bien nunca nos ha abandonado, en tiempo de problemas sanitarios ha estado más latente que nunca. Tal como lo sugiere el autor, al parecer ante hechos traumáticos solemos echar la culpa al "otro», al ajeno, al foráneo. No es un secreto ni tampoco un mito que la mayoría de las miles de víctimas ${ }^{6}$ del terrorismo fueron personas de origen andino, pero que, según el imaginario social criollo, no son víctimas porque «de seguro eran terroristas ${ }^{7}$. Los ciudadanos chinos, o sus descendientes, fueron estigmatizados por el inicio de la pandemia del coronavirus; el estigma iba más allá del rechazo social y se concretaba en el maltrato físico aleatorio. Los migrantes venezolanos, si bien no fueron acusados de

5 Información contextual al 13 de julio de 2021.

6 La Comisión de la Verdad y Reconciliación (CVR) estima que las acciones de Sendero Luminoso ocurridas de 1980 a 2000 ocasionaron alrededor de 37000 víctimas.

7 El actual fenómeno del «terruqueo» ha sido recientemente reseñado en la literatura. Para más detalles puede observarse: https://www.revistaideele.com/2021/05/04/diez-ideas-para-entender-el-terruqueo-hoy-una-guia-rapida-y-pormenorizada/ 
traer el virus, sí sufrieron nuestra xenofobia a raíz de la crisis laboral por la cuarentena impuesta por el Estado. La revisión de distintos momentos de nuestra historia sanitaria nacional que lleva a cabo Marcel Velázquez evidencia que el racismo se aviva en tiempos de epidemias. Al parecer, en estos periodos el imaginario limeño criollo redescubre la solución de todos nuestros males: la expulsión de todos los extranjeros no blancos.

La última sección trata del humor. La realidad supera con creces las creaciones (caricaturas, sátiras, cuentos, etc.) que ironizan con las conductas sociales. La misma realidad puede desatar más risas o carcajadas que los productos humorísticos. Marcel Velázquez apunta la compra exagerada del papel higiénico, los desinfectantes contaminados, los remedios caseros que no son exclusivos del siglo XXI, etc. Tal parece que el miedo a la enfermedad y a la muerte no solo hacen al ser humano más religioso, sino también más ingenuo. En tiempos de la covid-19, en pleno siglo XXI, los noticieros han transmitido reportajes sobre chamanes que prometen curar el coronavirus, actos que denuncian y condenan, aunque los mismos periodistas no fueron tan rígidos al momento de informar sobre la ivermectina, medicamento rechazado por el propio Ministerio de Salud en el tratamiento contra la enfermedad. Asimismo, resultaba muy gracioso (quizá indignante sea un término más adecuado) ver cómo la prensa asumió otros roles además del de informar: vigilancia y censura de las conductas ciudadanas. Durante los primeros meses de pandemia no era extraño ver a periodistas hostigando a las personas en las calles por no respetar la cuarentena o exigiendo permisos de tránsito. Algunos incluso seguían por varias cuadras a cuanto transeúnte encontraran por las calles, sin importar si se desplazaban dentro del horario permitido (Vigo, 2020). Estas imágenes de civiles armados con micrófonos y cámaras contrastaban con policías serviciales y pacíficos que parecían reconocer la autoridad de la prensa y hasta agradecerles por entorpecer su labor.

Los ensayos que componen Hijos de la peste nos hacen reflexionar sobre nuestras acciones y conductas en tiempos de crisis, épocas en las que el miedo nos controla y hace que anulemos nuestra racionalidad y sentido común. Estos momentos nos sorprenden y nos encuentran con la guardia baja, pese a que no son periodos aislados o poco comunes. Bien dicen que es importante el conocimiento de nuestra historia para no repetir los errores del pasado; debe ser por eso que hemos sido uno de los países con peor manejo de la pandemia, pese a haber soportado una de las cuarentenas más rígidas y extensas a nivel mundial. La ineficiencia de nuestro Estado se ha hecho latente en cada decisión absurda, y se reafirmaba con la alta aprobación del expresidente Vizcarra. "Si hay aprobación a la figura presidencial, ¿por qué tomar nuevas medidas?», 
parece que se hubiera preguntado Martín Vizcarra en cada anuncio de la extensión de la cuarentena. Así, este libro ayudará a que nos miremos como sociedad y reflexionemos sobre nuestras conductas y prácticas en tiempos de pandemia.

Resulta paradójico que, en este momento histórico próximo al bicentenario de nuestra independencia, realicemos las celebraciones desde el confinamiento, es decir, desde el encierro. Pero no es solo un encierro producto del virus, porque ya en otras latitudes la normalidad poco a poco se va reinstaurando. Si el bicentenario es sinónimo de celebración de libertad, los peruanos no tenemos nada que celebrar: partidos políticos de escasa convocatoria y envueltos en casos de corrupción, presidentes que se suceden unos tras otros por deseos subalternos, instituciones ineficientes, una lenta recuperación de la economía tras el cierre total de fronteras y paralización de actividades económicas nos han hecho ver que somos una nación dependiente, no solo de un sistema capitalista (Ayala-Colqui, 2020), sino también de los antojos y necesidades de una élite -a la que Méndez (2021) Ilama «cavernícolas ilustrados»— con pocas dotes de estadista. 


\section{REFERENCIAS BIBLIOGRÁFICAS}

Asensio, R. (2020). Introducción. En R. Asensio (Ed.), Crónica del gran encierro. Pensando el Perú en tiempos de pandemia (pp. 11-19). https:// iep.org.pe/wp-content/uploads/2020/06/Cr\%C3\%B3nica-del-GranEncierro-1.pdf

Ayala-Colqui, J. (2020). Viropolitics and capitalistic governmentality: On the management of the early 21 st century pandemic. Desde el Sur, 12(2), 377-395.

Bolo-Varela, O. (2020). Diez ideas para entender el terruqueo hoy: una guía rápida y pormenorizada. Revista Ideele, 297. https://www.revistaideele. com/2021/05/04/diez-ideas-para-entender-el-terruqueo-hoy-una-guiarapida-y-pormenorizada/

Llanos, F. (2020, 20 de julio 20). La verdad sobre el peruano que dice trabajar en una vacuna contra el COVID-19 en China. Canal N. https:// canaln.pe/actualidad/verdad-sobre-peruano-que-dice-trabajar-vacunacontra-covid-19-china-n420708

Méndez, C. (2021, 5 de julio). Cavernícolas ilustrados, golpistas y gamonales. La República. https://larepublica.pe/opinion/2021/07/05/ cavernicolas-ilustrados-golpistas-y-gamonales-por-cecilia-mendez/

Nieves-Cuervo, G., Manrique-Hernández, E., Robledo-Colonia, A. y GrilloArdilla, E. (2021). Infodemia: noticias falsas y tendencias de mortalidad por COVID-19 en seis países de América Latina. Revista Panamericana de Salud Pública, 45, 1-8. https://iris.paho.org/handle/10665.2/53901

Velázquez, M. (2020). Hijos de la peste. Una historia de las epidemias en el Perú. Taurus.

Vigo Cruzado, F. X. E. (2020). El tratamiento informativo de la televisión peruana sobre el cumplimiento de las recomendaciones sanitarias en Lima durante el COVID19. [Trabajo de investigación de bachillerato, Universidad Científica del Sur]. 